\title{
Association of ADAM33 Gene Polymorphisms with Keloid Scars in a Northeastern Chinese Population
}

\author{
Jianyu Han ${ }^{\mathrm{a}}$ Jianfeng Han ${ }^{\mathrm{b}}$ Dongmei Yu ${ }^{\mathrm{a}}$ Jinling Xiao ${ }^{c}$ Yong Shang ${ }^{\mathrm{a}}$ Lijun Hao
}

aPlastic and Cosmetic Center, The First Affiliated Hospital of Harbin Medical University, ${ }^{b}$ Orthopedics Department, The Second Affiliated Hospital of Harbin Medical University, cMedical Teaching and Research Section, The Second Affiliated Hospital of Harbin Medical University, Harbin, P.R. China

\section{Key Words}

Keloid scar • ADAM33 • Single nucleotide polymorphism • Association study

\begin{abstract}
Objective: To study the association between ADAM33 and keloid scars in the northeastern Chinese population. Methods: A total of 283 keloid scar patients and a control group of 290 healthy volunteers were recruited for this study. Six polymorphic loci (V4, T+1, T2, T1, S2 and Q-1 ) of ADAM33 were selected for genotyping. Genotypes were determined by using the polymerase chain reaction-restriction fragment length polymorphism (PCR-RFLP) method. Results: We observed the frequency of the rs612709 A allele exhibited a significantly decreased frequency in cases than in controls $(22 \mathrm{vs.39.6 \% ,P<0.0001)} \mathrm{We} \mathrm{also} \mathrm{found} \mathrm{that} \mathrm{the} \mathrm{frequencies}$ of $\mathrm{H} 2$ (GGAAGA) haplotypes was significantly higher in the case group than in the control group $(P=0.041)$. In contrast, the haplotype H8 (GGGAGG) was more common in the control group than in the case group $(P=0.022)$. Conclusions: Our data suggest that the ADAM33 polymorphisms may be associated with keloid scars in the northeastern Chinese population.
\end{abstract}

Copyright $(2014$ S. Karger AG, Basel

\section{Introduction}

The formation of keloid scars(KS) after skin trauma is a significant clinical problem . They can actively persist for many years. Keloid scars and hypertrophic scars have a similar clinical appearance of excessive scarring. They are characterized by overproduction 
of the extracellular matrix, mainly type I collagen, fibronectin and proteoglycans, but keloids, unlike hypertrophic scars, show a tendency to grow beyond the sites of original injury without spontaneous regression [1]. After early stage of granulation, with predominance of macrophages and increasing number of fibroblasts synthetizing new extracellular matrix, tissue remodelling occurs through granulation tissue contraction. Keloid scar is a familial condition [2], occurring more commonly in ethnic groups with darker skin [3]. The highest incidence of keloids is found in the black population, where it has been estimated to be around $4-6 \%$ and up to $16 \%$ in random samples of black Africans [4]. The mechanism of keloid scar formation is largely unknown [5, 6]. As increased familial aggregation, a higher prevalence in certain races, parallelism in identical twins, and alterations in gene expression favor the contribution of genetic risk factors to the development of keloid scar [7], researchers proposed that the mode of inheritance in keloid scar is autosomal recessive; [8] however, no single gene has yet been identified. Some genetic markers have been reported to have significant importance in diagnosis, prognosis, and development of keloid scar.

A disintegrin and metalloprotease 33 (ADAM33) gene, is a member of ADAM family. ADAM33 protein is a zinc-dependent endopeptidase, with pro-domain, catalytic, disintegrinlike, cysteine rich and epidermal growth factor-like domain [9]. It is abundantly expressed in smooth muscle and fibroblasts [10]. ADAM proteins are involved in cell adhesion, cell fusion, cell signaling, and proteolysis $[9,11]$. The latter can be illustrated by the capacity to shed cytokines, growth factors, or their receptors from the cell surface and the remodeling of extracellular matrix compo-nents. Garlisi demonstrated that ADAM33 is an active proteinase that is able to cleave $\alpha 2$-macroglobulin [12] and synthetic peptides [13]. The enzymatic activity of ADAM33 can be inhibited by tissue inhibitor of metalloproteinase- 3 and -4 (TIMP-3 and -4, respectively) as well as several small molecules [13]. This suggests that ADAM33 is involved in pulmonary defenses and tissue remodeling. Van Eerdewagh found the SNPs in ADAM33 gene was associated with asthma and bronchial hyper-responsiveness, it is the first time that ADAM33 gene was identified as a susceptibility gene for bronchial hyper-responsiveness by positional cloning techniques [11]. Furthermore, ADAM33 has been correlated with many cutaneous inflammatory and immune-mediated disorders [1416]. We used a case-control study to systematically investigate the association between ADAM33 polymorphisms and keloid scar. We determined the prevalence of single nucleotide polymorphisms (SNPs) and haplotypes of the ADAM33 gene using 573 samples (283 keloid scar patients and 290 healthy controls) from the Han population of northeastern China. Our study provides significant data to support the involve- ment of ADAM33 in the pathogenesis of keloid scar.

\section{Materials and Methods}

The case-control study consisted of 283 northeastern Chinese individuals with keloid, and 290 healthy Chinese individuals as controls. 283 keloid patients whose diagnose was confirmed by dermatologists in the First Affiliated Hospital of Harbin Medical University. Rigorous clinical criteria were used to differentiate KD from HTS, to limit the potentially confounding effects of misdiagnosis. We defined a keloid scar as a dermal lesion that had spread beyond the margins of the original wound, continued to grow over time, not regressed spontaneously commonly following excision and been present for a minimum of 1 year.

All the patients were interviewed, and a full medical history was obtained using a proforma. Every patient's scar was examined and photographed. 290 healthy individuals with no personal or family history of abnormal scar, were selected from Medical Examination Center of the First Affiliated Hospital of Harbin Medical University as controls. The detail characters were shown in Table 1.All individuals both in case and control groups were informed consent. The study was carried out with the approval of the clinical research ethics committee of Harbin Medical University. Genomic DNA was extracted from $200 \mu$ l of peripheral blood using the Qiamp DNA Blood Mini Kit (Qiagen, Germany) and following the manufacturer's protocols. 
Table 1. Description of the studied populations

\begin{tabular}{lcc}
\hline & case & Control \\
\hline Number of patients & 283 & 290 \\
age & $43.6(7.1)$ & $52.6(12.8)$ \\
male & 101 & 124 \\
& & \\
\hline
\end{tabular}

Table 2. Description of the investigated ADAM33 SNPs

\begin{tabular}{|c|c|c|c|c|}
\hline Chromosome Position SNP ID & Reference & SNP Name & Allels & Primer Sequences \\
\hline 3589161 & 2787094 & V4 & $C / G$ & $\begin{array}{l}\text { F: 5'-ACACACAGAATGGGGGAGAG-3' } \\
\text { R: 5'-CCAGAAGCAAAGGTCACACA-3' }\end{array}$ \\
\hline 3590127 & 2280089 & $\mathrm{~T}+1$ & $\mathrm{~A} / \mathrm{G}$ & $\begin{array}{l}\text { F: 5'-CTGAGCCCAGAAACCTGATT-3' } \\
\text { R: 5'-AGAAGGGAAGGGCTCATGC-3' }\end{array}$ \\
\hline 3590205 & 2280090 & $\mathrm{~T} 2$ & $\mathrm{~A} / \mathrm{G}$ & $\begin{array}{l}\text { F: 5'-TTCTCAGGGTCTGGGAGAAA-3' } \\
\text { R: 5'-GCCAACCTCCTGGACTCTTA-3' }\end{array}$ \\
\hline 3590234 & 2280091 & T1 & $\mathrm{A} / \mathrm{G}$ & $\begin{array}{l}\text { F: 5'-ACTCAAGGTGACTGGGTGCT-3' } \\
\text { R: 5'-GAGGGCATGAGGCTCACTTG-3' }\end{array}$ \\
\hline 3591742 & 528557 & S2 & $\mathrm{C} / \mathrm{G}$ & $\begin{array}{l}\text { F: 5'-AGAGCTCTGAGGAGGGGAAC-3' } \\
\text { R: 5'-TGTGCAGGCTGAAAGTATGC-3' }\end{array}$ \\
\hline 3592207 & 612709 & Q-1 & $\mathrm{A} / \mathrm{G}$ & $\begin{array}{l}\text { F: 5'-GGATTCAAACGGCAAGGAG -3' } \\
\text { R: 5'-GTTCACCTAGATGGCCAGGA-3' }\end{array}$ \\
\hline
\end{tabular}

Table 3. The frequencies of genotypes in ADAM33

\begin{tabular}{|c|c|c|c|c|c|}
\hline \multirow{2}{*}{ SNP } & \multirow{2}{*}{ Genotype } & \multicolumn{2}{|c|}{ Frequency (\%) } & \multirow{2}{*}{$P$-Value } & \multirow{2}{*}{$\begin{array}{l}\text { Odds ratio and Confidence } \\
\text { intervals ( } 95 \% \mathrm{CI}) \\
\end{array}$} \\
\hline & & Case (283) & Control (290) & & \\
\hline \multirow{3}{*}{$\begin{array}{l}\text { rs2787094 } \\
\text { (V4) }\end{array}$} & $\mathrm{CC}$ & $69(0.2438)$ & 78 (0.2689) & 0.491 & $0.876(0.602-1.276)$ \\
\hline & CG & $94(0.3321)$ & $97(0.3345)$ & 0.953 & $0.990(0.699-1.401)$ \\
\hline & GG & $120 \quad(0.4240)$ & $115(0.3966)$ & 0.504 & $1.120(0.803-1.563)$ \\
\hline \multirow{3}{*}{$\begin{array}{l}\mathrm{rs} 2280089 \\
(\mathrm{~T}+1)\end{array}$} & $\mathrm{AA}$ & $30(0.1060)$ & $25(0.0862)$ & 0.422 & $1.257(0.719-2.196)$ \\
\hline & AG & $64(0.2261)$ & $51(0.1759)$ & 0.133 & $1.370(0.908-2.066)$ \\
\hline & GG & $189(0.6678)$ & $214(0.7379)$ & 0.067 & $0.714(0.498-1.024)$ \\
\hline \multirow{3}{*}{$\begin{array}{l}\text { rs } 2280090 \\
\text { (T2) }\end{array}$} & GG & $189(0.6678)$ & $182(0.6276)$ & 0.314 & $1.193(0.846-1.682)$ \\
\hline & AG & $86(0.3039)$ & $99(0.3414)$ & 0.338 & $0.842(0.593-1.196)$ \\
\hline & $\mathrm{AA}$ & $8(0.0283)$ & $9(0.0310)$ & 0.845 & $0.908(0.345-2.388)$ \\
\hline \multirow{3}{*}{$\begin{array}{l}\text { rs } 2280091 \\
\text { (T1) }\end{array}$} & AA & $215(0.7597)$ & $236(0.8138)$ & 0.114 & $0.723(0.484-1.082)$ \\
\hline & AG & $63(0.2226)$ & $50(0.1724)$ & 0.131 & $1.375(0.909-2.079)$ \\
\hline & GG & $5(0.0177)$ & $4(0.0138)$ & 0.709 & $1.286(0.342-4.839)$ \\
\hline \multirow{3}{*}{$\begin{array}{l}\text { rs528557 } \\
\text { (S2) }\end{array}$} & $\mathrm{CC}$ & $28(0.0989)$ & $17(0.0586)$ & 0.073 & $1.763(0.943-3.299)$ \\
\hline & CG & $79(0.2792)$ & $88(0.3034)$ & 0.523 & $0.889(0.620-1.275)$ \\
\hline & GG & $176(0.6219)$ & $185(0.6379)$ & 0.691 & $0.934(0.665-1.311)$ \\
\hline \multirow{3}{*}{$\begin{array}{l}\text { rs612709 } \\
(\mathrm{Q}-1)\end{array}$} & $\mathrm{AA}$ & $12(0.0424)$ & $53(0.1828)$ & $<0.0001$ & $0.198(0.103-0.379)$ \\
\hline & AG & $101(0.3569)$ & $124(0.4276)$ & 0.083 & $0.743(0.531-1.040)$ \\
\hline & GG & $170(0.6007)$ & $113(0.3897)$ & $<0.0001$ & $2.356(1.686-3.295)$ \\
\hline
\end{tabular}

\section{SNP Genotyping}

Genotyping was performed by polymerase chain reaction-restriction fragment length polymorphism (PCR-RFLP) analysis. The polymorphic region was amplified by PCR using a T-Gradient Thermoblock PCR System (Iometra, Germany) in a $25 \mu \mathrm{l}$ reaction solution containing $0.3 \mu$ g genomic DNA, 10× PCR buffer, $0.3 \mathrm{mM} \mathrm{MgCl}, 0.2 \mathrm{mM}$ dNTPs, 2 U TaqDNA polymerase (Takara, Japan), and $0.1 \mu \mathrm{mol}$ of each primer (Invitrogen, USA). Six SNPs in ADAM33 (V4[rs2787094], T+1[rs2280089],T2[rs2280090], T1[rs2280091], S2[rs528557] and Q-1[rs612709])were investigated in this case-control study. SNP names and primer sequences are listed in Table 2. According to the manufacturer's instructions, PCR products were digested overnight with restriction enzymes (NEB, UK)and analyzed by agarose gel electrophoresis. 


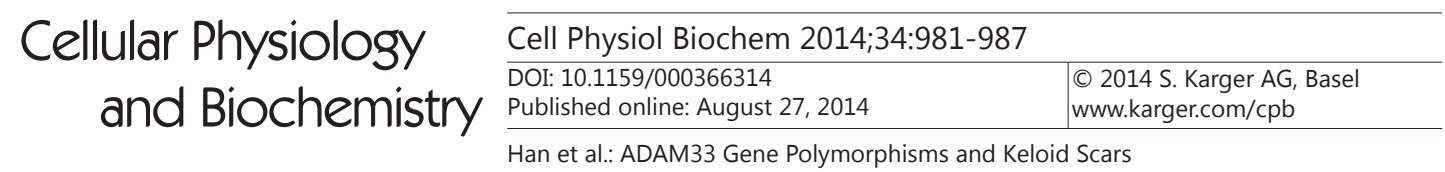

Table 4. The frequencies of alleles of ADAM33

\begin{tabular}{|c|c|c|c|c|c|}
\hline SNP & Allele & $\begin{array}{l}\text { Minor allel } \\
\text { case(283) }\end{array}$ & $\begin{array}{r}\text { frequency }(\%) \\
\text { control(290) }\end{array}$ & $P$-Value & $\begin{array}{l}\text { Odds ratio and Confidence } \\
\text { intervals }(95 \% \mathrm{CI})\end{array}$ \\
\hline $\begin{array}{l}\text { rs2787094 } \\
\text { (V4) }\end{array}$ & C:G & 0.4099 & 0.4362 & 0.368 & $0.898(0.710-1.135)$ \\
\hline $\begin{array}{l}\mathrm{rs} 2280089 \\
(\mathrm{~T}+1)\end{array}$ & $A: G$ & 0.2191 & 0.1741 & 0.056 & $1.330(0.993-1.783)$ \\
\hline $\begin{array}{l}\text { rs2280090 } \\
\text { (T2) }\end{array}$ & $A: G$ & 0.1802 & 0.2017 & 0.355 & $0.870(0.648-1.168)$ \\
\hline $\begin{array}{l}\text { rs2280091 } \\
\text { (T1) }\end{array}$ & G:A & 0.1290 & 0.1000 & 0.123 & $1.333(0.924-1.922)$ \\
\hline $\begin{array}{l}\text { rs528557 } \\
\quad \text { (S2) }\end{array}$ & $\mathrm{C}: \mathrm{G}$ & 0.2385 & 0.2103 & 0.253 & $1.176(0.891-1.553)$ \\
\hline $\begin{array}{l}\text { rs612709 } \\
(\mathrm{Q}-1)\end{array}$ & $A: G$ & 0.2208 & 0.3966 & $<0.0001$ & $0.431(0.333-0.559)$ \\
\hline
\end{tabular}

Table 5. The distribution of haplotypes of ADAM33

\begin{tabular}{|c|c|c|c|c|c|c|c|c|c|c|c|}
\hline \multirow{2}{*}{$\frac{\sum_{0}^{2}}{\frac{0}{2}}$} & \multirow{2}{*}{ 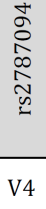 } & \multirow{2}{*}{ 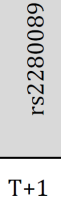 } & \multirow{2}{*}{ 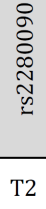 } & \multirow{2}{*}{ 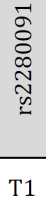 } & \multirow{2}{*}{ 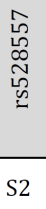 } & \multirow{2}{*}{ 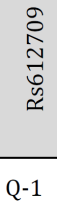 } & \multirow{2}{*}{$\begin{array}{c}\text { Frequency } \\
(\%)\end{array}$} & \multicolumn{2}{|c|}{ Frequency (\%) } & \multirow{2}{*}{$\begin{array}{c}P- \\
\text { Value }\end{array}$} & \multirow{2}{*}{$\begin{array}{l}\text { Odds ratio and } \\
\text { Confidence } \\
\text { intervals }(95 \% \mathrm{CI})\end{array}$} \\
\hline & & & & & & & & case(283) & control(290) & & \\
\hline $\mathrm{H} 1$ & $\mathrm{G}$ & G & G & A & G & A & 0.174 & 0.159 & 0.190 & 0.334 & $0.808(0.524-1.246)$ \\
\hline $\mathrm{H} 2$ & $\mathrm{G}$ & G & A & A & $\mathrm{G}$ & A & 0.168 & 0.201 & 0.134 & 0.041 & $1.583(1.617-2.463)$ \\
\hline H3 & $\mathrm{C}$ & G & $\mathrm{G}$ & G & $\mathrm{C}$ & A & 0.122 & 0.113 & 0.131 & 0.512 & $0.845(0.512-1.396)$ \\
\hline $\mathrm{H} 4$ & $\mathrm{C}$ & G & G & G & G & A & 0.063 & 0.057 & 0.069 & 0.540 & $0.809(0.410-1.595)$ \\
\hline H5 & $\mathrm{G}$ & G & G & A & $\mathrm{C}$ & A & 0.057 & 0.053 & 0.062 & 0.642 & $0.846(0.418-1.713)$ \\
\hline H6 & $\mathrm{G}$ & G & G & G & G & A & 0.031 & 0.035 & 0.028 & 0.595 & $1.291(0.502-3.320)$ \\
\hline H7 & G & G & G & G & $\mathrm{G}$ & G & 0.023 & 0.028 & 0.017 & 0.376 & $1.658(0.536-5.131)$ \\
\hline H8 & $\mathrm{C}$ & G & $\mathrm{G}$ & A & G & G & 0.021 & 0.007 & 0.034 & 0.022 & $0.199(0.043-0.918)$ \\
\hline H9 & $\mathrm{G}$ & A & A & G & $\mathrm{C}$ & A & 0.020 & 0.021 & 0.017 & 0.730 & $1.235(0.373-4.092)$ \\
\hline H10 & $\mathrm{C}$ & G & G & A & $\mathrm{G}$ & A & 0.018 & 0.018 & 0.017 & 0.969 & $1.025(0.294-3.580)$ \\
\hline H11 & $\mathrm{G}$ & $\mathrm{G}$ & $\mathrm{G}$ & A & $\mathrm{C}$ & $\mathrm{G}$ & 0.011 & 0.007 & 0.014 & 0.429 & $0.509(0.092-2.801)$ \\
\hline
\end{tabular}

Statistical analysis

Each SNP was tested for deviation from Hardy-Weinberg equilibrium (HWE) using chi-square with expected frequencies derived from allele frequencies. Frequencies of each allele and genotypes were calculated directly and chi-square tests were carried out using SPSS software for windows (Version 13.0; SPSS Inc, Chicago, IL), significance was defined as $p<0.05$. Haplotype block was constructed in Haploview 4.1 software (http://www.broad.mit.edu/mpg/haploview). The relative association with rare alleles was estimated as an odds ratio (OR) with a $95 \%$ confidence interval (CI).

\section{Results}

Frequency distributions in alleles and genotypes of ADAM33 polymorphisms

Deviations from Hardy-Weinberg equilibrium were not seen in case and healthy groups for any of six SNPs. The genotype and allele frequencies of all six ADAM33 SNPs in the two groups are shown in Table 3 and Table 4. The genotype frequencies of Q-1[rs612709] AA, CG were higher in keloid scar groups than those in controls $(\mathrm{P}<0.0001, \mathrm{OR}=0.198,95 \%$ $\mathrm{CI}=0.103-0.379$ and $\mathrm{p}<0.0001, \mathrm{OR}=2.356,95 \% \mathrm{CI}=1.686-3.295$, respectively) (shown in Table 3). As shown in Table 4, the frequency of the rs612709 A allele exhibited a significantly 
decreased frequency in cases than in controls (22 vs.39.6\%, $\mathrm{P}<0.0001$ ). In contrast, we did not find statistically significant differences in the allele frequencies in V4[rs2787094], $\mathrm{T}+1$ [rs2280089], T2[rs2280090], T1[rs2280091], S2[rs528557] between cases and controls and these polymorphisms were not associated with keloid scar.

\section{ADAM33 haplotype analysis}

The haplotypes of cases and controls were constructed using Haploview 4.1 software. The haplotypes were selected for further analysis which frequencies were not less than $1.0 \%$. There were 11 haplotypes in all samples. Haplotype analysis showed that the frequencies of H2 (GGAAGA) haplotypes was significantly higher in the case group than in the control group $(P=0.041$,). In contrast, the haplotype H8 (GGGAGG) was more common in the control group than in the case group $(P=0.022)$. The details were seen in Table 5.

\section{Discussion}

The present study is the first demonstration of an association between ADAM33 polymorphisms and keloid scar in an East Asian population. Using a case-control design, we investigated the relationship between human peripheral blood ADAM33 polymorphisms and keloid scar in northeast China. Our results showed that the Q-1 SNPs in blood was significantly associated with keloid scar. As multiple SNPs may act in combination to increase the risk of keloid scar, haplotypes were constructed, and their frequencies were compared between the case and control groups. The haplotype data suggests that the GGAAGA haplotypes may be risk factor for keloid scar. In contrast, the GGGAGG haplotype may be a protective factor for the disease.

Keloid is defined as a scar growing continuously and invasively beyond the confines of the original wound and is characterized by excessive fibroblast proliferation and deposition of extracellular matrix and collagen fibers [17]. Although the familial nature of the disease and its reported presence in identical twins has long indicated a genetic component to keloid scar pathology ,the exact aetiopathogenesis of keloid scar is unknown [18, 19]. Genetic studies have yet to identify a gene or genes involved in keloid scar. Using a case-control association study approach, it is possible to attempt to test candidate gene loci that may be involved in keloid scar pathogenesis.

There are more than 30 members of the ADAM (adisintegrin and metalloprotease) family of proteins with orthologues in several species.ADAM33 gene, mapped on chromosome 20p13, is a member of ADAM family. ADAMs are membrane-anchored metalloproteases that play key roles in cell-to-cell interactions and shedding of pro-protein ectodomains [20, 21]. ADAM33 protein is a zinc-dependent endopeptidase, characterized by a pro-domain, metallo-protease, and disintegrin domains, a cysteine-rich region sometimes containing an EGF repeat, a transmembrane domain, and a cytoplasmic carboxyl-terminus. [9]. ADAM33 gene was identified to be associated with asthma and airway hyperresponsiveness (AHR) by positional cloning [11]. Furthermore, ADAM33 has been correlated with many immune mediated disorders [14-16]. And that, many researchers assessed the expression of ADAM33 protein in human lung tissue, primary bronchial smooth muscle cells, and a fibroblast cell line (MRC-5).ADAM33 belongs to a family of type I transmembrane metalloproteinases. These integral membrane glycoproteins play important physiological roles in fertilization, myogenesis, and neurogenesis due to their participation in cell-cell interactions and proteolytic release of cell surface membrane proteins such as cytokines, growth factors,and receptors $[22,23]$. Q-1 is located in the intron immediately before exon 16 , which contains an epidermal growth factor (EGF) domain [24]. ADAM33 is closely related to matrix metalloproteases, but may bind EGF directly. A disturbance in the EGF domain will likely affect regulation of ADAM33. Through alterative splicing, exon 16 can be spliced out, giving rise to the $\beta$-variant of ADAM33. This variant was found in 30\% of ADAM33 mRNA transcripts in pulmonary fibroblasts [23]. Because the EGF domain is incom-plete, it has been suggested that the $\beta$-variant prevents maturation of ADAM33 and may exert a dominant negative effect 
Han et al.: ADAM33 Gene Polymorphisms and Keloid Scars

on its protease activity [25]. The intronic Q-1 SNP may therefore influence the splicing of the $\beta$-variant and disturb the maturation of ADAM33. Subsequent effects on protease activity may result in a defect in tissue repair after inflammation-induced damage. This may be involved in the mechanism of keloid scar formation.

Several limitations in this study need to be addressed. This study was a single-center cohort investigation on a relatively small scale, and thus, replication studies with large independent cohorts are warranted. Secondly, we did not detect the ADAM33 expression in keloid scar tissue. Based on the results in blood sample, next we will perform the experiment in human tissue. The detection of ADAM33 protein will help to clarify the effect of the genetic variants of ADAM33 gene on keloid scar formation.

\section{Conclusion}

In summary, our results suggest that the ADAM33 gene polymorphism was associated with keloid scars in the northeastern Chinese Han population.

\section{Disclosure Statement}

The authors declare no competing interests.

\section{Acknowledgements}

This work was funded by the Heilongjiang provincial health department, China (No.2007-202). We thank Dr. Liu Wei for her help in the SNP Genotyping. We also thank the blood donor for the study.

\section{References}

1 Friedman DW, Boyd CD, Mackienzie JW: Regu- lation of collagen expression in keloids and hypertrophic scars. J Surg Res 1993;55:214-222.

2 Bayat A, Arscott G, Ollier WER: Keloid disease: clinical rele- vance of single versus multiple site scars. Br J Plast Surg 2005;58:28-37.

-3 Bayat A, Arscott G, Ollier WER: Description of site-specific morphology of keloid phenotypes in an Afrocaribbean population. Br J Plast Surg 2004;57:122-33.

4 Bloom D: Heredity of keloids. Review of the literature and report of a family with multiple keloids in five generations. NY State Med J 1956;56:511-519.

-5 Ehrlich HP, Desmouliere A, Diegelmann RF, Cohen IK, Compton CC, Garner WL, Kapanci Y, Gabbiani G: Morphological and immunochemical differences between keloid and hypertrophic scar. Am J Pathol 1994;145:105-113.

6 Rossiello L, D'Andrea F, Grella R, Signoriello G, Abbondanza C, De Rosa C, Prudente M, Morlando M, Rossiello R: Differential expression of cyclooxygenases in hypertrophic scar and keloid tissues. Wound Repair Regen 2009;17:750-757.

7 Halim AS, Emami A, Salahshourifar I, Kannan TP: Keloid scarring: understanding the genetic basis, advances, and prospects. Arch Plast Surg 2012;39:184-189.

-8 Omo-Dare P: Genetic studies on keloid. J Natl Med Assoc 1975;67:428-32.

$>9$ Sampsonas F, Kaparianos A, Lykouras D, Karkoulias K, Spiropoulos K: DNA sequence variations of metalloproteinases: their role in asthma and COPD. Postgrad Med J 2007;83:244-250. 
10 Postma DS, Howard T: ADAM33 gene: confirming a gene with-out linkage. Clin Exp Allergy 2004;34:1-3.

11 Van Eerdewegh P, Little RD, Dupuis J: Association of the ADAM33 gene with asthma and bronchial hyperresponsiveness. Nature 2002;418:426-430.

12 Datubo-Brown DD: Keloids: a review of the literature. Br J Plast Surg 1990;43:70-77.

13 Roberts AB, Sporn MB: Transforming growth factor 13. Adv Cancer Res 1988;51: 107-45.

14 Smyth DJ, Howson JM, Payne F, Maier LM, Bailey R, Holland K, Lowe CE, Cooper JD, Hulme JS, Vella A, Dahlman I, Lam AC, Nutland S, Walker NM, Twells RC, Todd JA: Analysis of polymorphisms in 16 genes intype 1 diabetes that have been associated with other immune-mediated diseases. BMC Med Genet 2006; 7:20-26.

15 Holloway JW, Laxton RC, Rose-Zerilli MJ, Holloway JA, Andrews AL, Riaz Z, WilsonSJ, Simpson IA, Ye S: ADAM33 expression in atherosclerotic lesions and relationship of ADAM33 gene variation with atherosclerosis.Atherosclerosis 2010;211:224-230.

16 Matsusue A, Kiyohara C, Tanaka K, Sasaki S, Miyake Y: ADAM33 genetic polymorphisms and risk of atopic dermatitis among Japanese children. Clin Biochem 2009;42:477-483.

17 Marneros AG, Krieg T: Keloids-clinical diagnosis, pathogenesis, and treatment options. J Dtsch Dermatol Ges 2004;2:905-913.

18 Dongmei Yu, Yong Shang, Sai Lu, Lijun Hao: The TaqI Gene Polymorphisms of VDR and the Circulating 1,25-Dihydroxyvitamin D Levels Confer the Risk for the Keloid Scarring in Chinese Cohorts. Cell Physiol Biochem 2013;32:39-45.

19 Marneros AG, Norris JE, Olsen B R, Reichenberger E: Clinical genetics of familial keloids. Arch Dermatol 2001;137:1429-1434.

20 Primakoff P, Myles DG: The ADAM gene family: surface proteins with adhesion and protease activity. Trends Genet 2000;16:83-87.

-21 Schlöndorff J, Blobel CP: Metalloprotease-disintegrins:modular proteins capable of promoting cell-cell interactions and triggering signals by protein-ectodomain shedding. J Cell Sci 1999;112:3603-3617.

22 Garlisi CG, Zou J, Devito KE, Tian F, Zhu FX, Liu J, Shah H, Wan Y, Motasim Billah M, Egan RW, Umland SP: Human ADAM33: protein maturation and localization Biochem Biophys Res Comm 2003;301:35-43.

-23 Powell RM, Wicks J, Holloway JW, Holgate ST, Davies DE: The splicing and fate of ADAM33 transcripts in primary human air-ways fibroblasts. Am J Respir Cell Mol Biol 2004;31:13-21.

24 Yoshinaka T, Nishii K, Yamada K, Sawada H, Nishiwaki E, Smith K, Yoshino K, Ishiguro H, Higashiyama S: Identification and charac-terization of novel mouse and human ADAM33s with poten-tial metalloprotease activity. Gene 2002;282:227-236.

25 Umland SP, Garlisi CG, Shah H, Wan Y, Zou J, Devito KE, Huang WM, Gustafson EL, Ralston R: Human ADAM33 messenger RNAexpression profile and post-transcriptional regulation. Am J Respir Cell Mol Biol 2003;29:571-582. 